\title{
Urban Storm-Water Quality Management: Centralized versus Source Control
}

\author{
Gabriele Freni'; Giorgio Mannina ${ }^{2}$; and Gaspare Viviani, P.E. ${ }^{3}$
}

\begin{abstract}
The continuous growth of urban areas and the increasing public awareness of the environmental impacts of storm water have raised interest on the quality of the receiving water bodies. In the past two decades, many efforts have been directed at improving urban drainage systems by introducing mitigation measures to limit the negative environmental impacts of storm water. These mitigation measures are generally called best management practices (BMPs), sustainable urban drainage systems, or low impact developments, and they include practices such as infiltration and storage tanks that reduce the peak flow and retain some of the polluting materials. Choosing the best mitigation measure is still a controversial topic. To gain insight on the best technique, this study compares different distributed and centralized urban storm-water management techniques, including infiltration and storage facilities. The main objective of this study is to use modeling to assess the effects of the different urban drainage techniques. To this end, a homemade model that was developed in previous studies is applied. This model enables us to simulate both combined sewer systems and ancillary structures such as storm tanks or infiltration trenches to determine water quantity and quality characteristics. A long-term simulation is employed to account for the effects of sediments in BMPs, which generally reduce the hydraulic capacity. The results allow us to draw some conclusions on the peculiarities of BMP techniques, on the possibility of integrating different techniques for improving efficiency, and on BMP maintenance planning.
\end{abstract}

DOI: 10.1061/(ASCE)0733-9496(2010)136:2(268)

CE Database subject headings: Best Management Practice; Combined sewers; Infiltration.

Author keywords: Best management practices; Receiving water impact; Urban water quality; Storm-water infiltration; Integrated urban drainage modeling..

\section{Introduction}

In recent years, the limitations of traditional urban drainage schemes have been acknowledged and new approaches that use more natural methods for retaining and/or disposing of storm water have been introduced (Emerson et al. 2005; Bledsoe 2002; Niemczynowicz 1994). These mitigation measures are generally called best management practice (BMP), sustainable urban drainage system (SUDS), or low impact development (LID), and they include practices such as infiltration and the use of storage tanks to reduce the peak flow, increase the catchment concentration time, and retain some of the polluting components. Out of all of the storm-water management practices, infiltration devices are the most effective at removing storm-water pollutants and reducing both the storm-water volume and peak discharge rate. Infiltration

\footnotetext{
${ }^{1}$ Research Assistant, Dipartimento di Ingegneria Idraulica ed Applicazioni Ambientali, Università di Palermo, Viale delle Scienze, 90128 Palermo, Italy. E-mail: freni@idra.unipa.it

${ }^{2}$ Research Assistant, Dipartimento di Ingegneria Idraulica ed Applicazioni Ambientali, Università di Palermo, Viale delle Scienze, 90128 Palermo, Italy (corresponding author). E-mail: mannina@idra.unipa.it

${ }^{3}$ Professor, Dipartimento di Ingegneria Idraulica ed Applicazioni Ambientali, Università di Palermo, Viale delle Scienze, 90128 Palermo, Italy. E-mail: gviv@idra.unipa.it

Note. This manuscript was submitted on April 2, 2008; approved on October 5, 2009; published online on February 12, 2010. Discussion period open until August 1, 2010; separate discussions must be submitted for individual papers. This paper is part of the Journal of Water Resources Planning and Management, Vol. 136, No. 2, March 1, 2010. (C)ASCE, ISSN 0733-9496/2010/2-268-278/\$25.00.
}

devices are inspired by the rural construction tradition and are based on storm-water collection during rainfall events and the subsequent infiltration into the soil (Freni and Schilling 2001; Mays 2001; ASCE 1998). Storage facilities represent a large family of storm-water management practices that have the following basic functions: water storage, peak dampening, catching a first flush, water treatment, and the disposal of the inflow runoff volume.

Although there are many different variants of storage devices, there are two basic management principles that are common to all of them:

- Detention: all or part of the runoff is stored temporarily and then gradually released into the drainage system. This approach does not allow for the disposal of the stored runoff.

- Retention: all or part of the runoff is stored for a long period and is not released into the drainage system or to the receiving watercourse. The stored runoff is usually disposed of through infiltration, evaporation, or various applications (landscaping or irrigation).

These practices are usually distributed over the catchment at locations near the source of the storm-water runoff (Alfakih et al. 1995; Sieker and Klein 1998; Freni et al. 2004; Hatt et al. 2006). For this reason, they are often classified as source controls or distributed measures. These techniques have advantages such as small dimensions, so that they can be fitted even in urbanized catchments, but they require complex maintenance procedures and can be costly especially considering cost/benefit with regard to pollutant removal. Apart from source controls, classical centralized in-pipe or end-of-pipe structures can also be used to meet the same receiving quality protection objectives (Niemczynowicz 


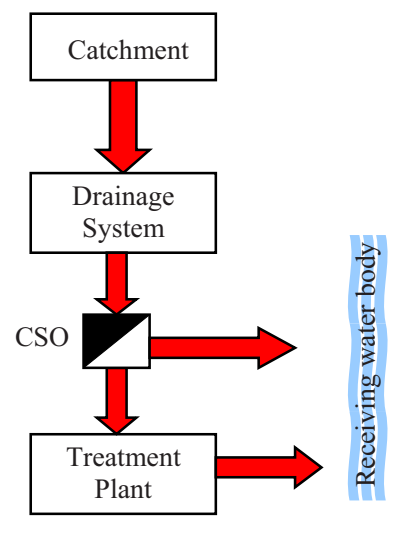

1) No mitigation measure

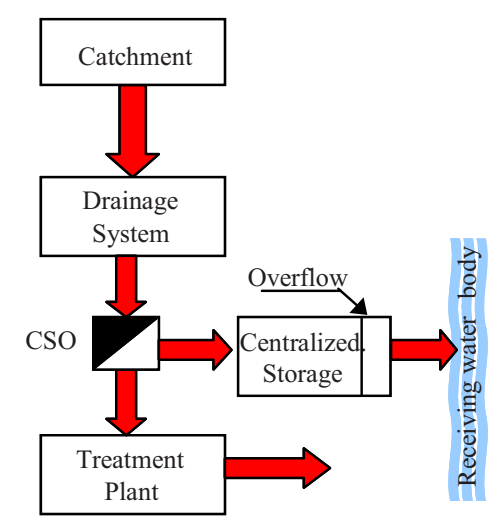

3) Centralised stormwater tank solution

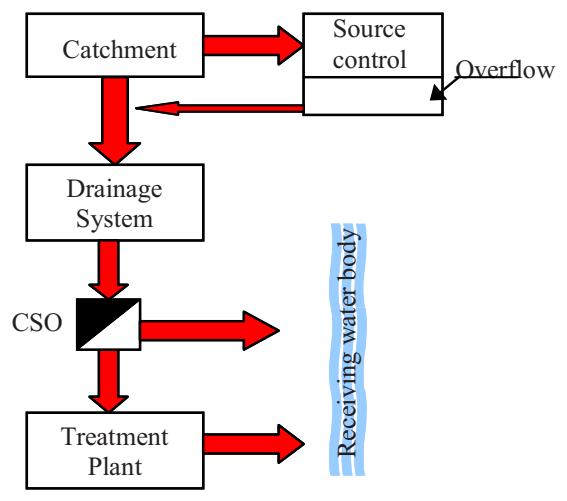

2) Distributed BMP solution

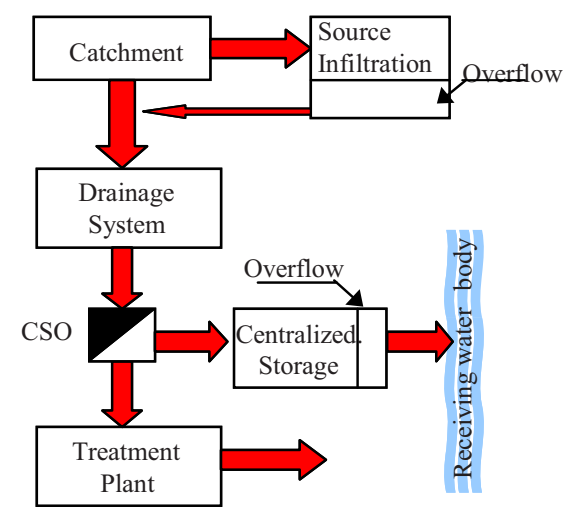

4) Mixed solution

Fig. 1. Studied storm-water mitigation planning schemes

1994; Hatt et al. 2004; 2007). These techniques usually involve storage facilities, while infiltration is adopted less often because of the higher risk of groundwater contamination and because of limitation in functionality by such factors as depth to bedrock, soil types (especially clayey soils), and high water table (Browne et al. 2008; Sansalone and Buchberger 1995). In brief, centralized practices have the opposite advantages and disadvantages with respect to source controls: their maintenance is usually cheaper, but fitting is more difficult because they require a larger space (Mays 2001). Source controls and centralized practices can also be combined to obtain hybrid solutions that are able to combine the advantages of the two types of mitigation measures.

The range of mitigation solutions (including source controls or centralized techniques) represents a problem in storm-water management planning because for every possible solution the efficiency has to be computed to choose the best solution. Moreover, a quality assessment of a receiving water body (RWB) usually requires long-term analysis or, as an alternative, the analysis of a representative number of historical events (Despotovic et al. 1995). Thus, computer simulations have proven to be the best tool for optimizing the design and operation of sewer systems (SSs) and wastewater treatment plants (WWTPs). Indeed, mathematical models enable engineers to evaluate different solutions prior to their construction. Also, dynamic models are increasingly used for optimizing integrated systems (i.e., the combination of SS, WWTP, and RWB).

A long-term analysis requires the development and use of ro- bust and parsimonious modeling approaches that provide information on the RWB quality and the impact of urban area discharges (Vaes and Berlamont 1999; Vaes and Berlamont 2004); by "parsimonious" we mean that the best approach is the simplest one that fits the application (Harremoës and Madsen 1999). This approach is more relevant if the study is aimed to evaluate the impact of urban combined sewer overflows (CSOs) on RWBs due to the complexity of the processes involved during wet periods and the short time scale on which they occur (Freni et al. 2008; Mannina 2005).

In the present paper, a comparison of a conventional SS configuration and three different mitigation planning schemes (Fig. 1 ), including source controls and centralized measures, is performed as follows:

- The first scheme is the control test, where no mitigation measure is used;

- The second scheme is the "source control" scenario in which mitigation is totally provided by source control as local infiltration (Scheme 2-a) or as source storage (Scheme 2-b);

- The third scheme is the "centralized mitigation" scenario in which storm-water management is provided by a storage tank connected to a CSO; and

- The fourth scheme contains "mixed configurations" where local infiltration and centralized storage are combined in an effort to gain the advantages of both of the mitigation techniques.

The effects of urban area characteristics that affect infiltration 
BMP efficiency (mainly, the soil types) were surveyed for this study. Infiltration BMPs were distributed over the catchment according to the design criteria that will be discussed in the following section; the centralized storage was located at the end of the SS and connected with the CSO.

As mentioned above, the analysis was performed using a parsimonious modeling approach that was developed in previous studies (Mannina 2005). This model enabled us to evaluate the mitigation efficiency of the different BMP schemes, including infiltration and storage facilities, and to consider the effectiveness of both source controls and centralized structures. In particular, the model was able to consider the presence of a BMP structure in different configurations (source controls, centralized structures, or combinations), making it a useful tool for urban storm-water quality management as well as planning purposes. Concerning the infiltration trenches, the model also takes into account hindrances to the performance due to clogging phenomena to outline some general considerations that can be used for design support. A long-term analysis was carried out for the six-year rain series recorded at the Parco d'Orlèans experimental catchment (Palermo, Italy).

\section{Model Description}

For the present study, an integrated model was applied to simulate the main processes in the catchment, SS, and for both source control and centralized mitigation techniques. Many efforts have been directed at creating simple yet robust methods for the longterm simulation and integrated analysis of several elements of drainage systems. Several reports are available that describe models of the phenomena in urban drainage systems (Artina et al. 2007; Tomicic et al. 1999; Huber 1996). Although the best way to simulate an entire drainage system is by adopting a detailed approach, such as using the de Saint-Venant equations for hydrodynamic routing, the calculation times for long-term simulations are too long; such equations are very time consuming, and simplifications are necessary for a feasible study. There are two alternatives to using the full equations: simplifying the rainfall input by considering synthetic rain events or simplifying the modeling approach. The former leads to a loss of information, and, as a consequence, the results are not reliable. Also, it is not possible to evaluate the emission probabilities even if detailed simulations with single events make the behavior of the system more comprehensive (Vaes and Berlamont 1999).

\section{Urban Drainage Model}

This model is able to simulate the main phenomena that take place in both the catchment and the sewer network during a storm event (Mannina et al. 2004; Mannina 2005; Mannina and Viviani 2009b). It is divided into two connected modules: (1) a hydrological and hydraulic module that calculates the hydrographs at the inlet and at the outlet of the SS and (2) a solid transport module that calculates the pollutographs at the outlet for the different pollutants, including the total suspended solids (TSS), biochemical oxygen demand (BOD), and chemical oxygen demand (COD). The hydrological-hydraulic module evaluates the net rainfall from the gross hyetograph using a loss function that accounts for the surface storage and soil infiltration. From the net rainfall, the model simulates the rainfall runoff at the catchment and the flow propagation in the SS with a cascade of two reservoirs. The

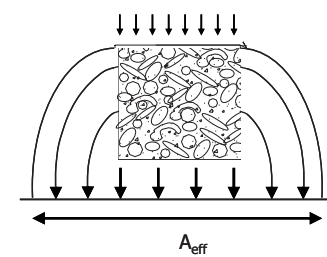

(a)

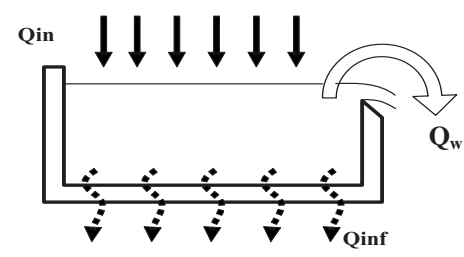

(b)
Fig. 2. Infiltration structure model schematization

water quality module simulates buildup by a classical Alley and Smith approach (Alley and Smith 1981), while the washoff during a storm event was simulated with the formulation by Jewell and Adrian (1978). The dry weather deposits in the sewers were evaluated by adopting an exponential law (Bertrand-Krajewski et al. 2006; Mannina 2005). Particular care has been taken for sediment transformations in sewers, considering their cohesivelike behavior linked to organic substances and to the physicochemical changes induced during sewer transport. The urban drainage model is also able to simulate the presence of CSO devices by the use of rating curves that take into account variations in the CSO efficiency that depend on the inflow discharge.

\section{Infiltration BMP Model}

The infiltration phenomena that take place around a BMP structure are generally three dimensional. Moreover, during the filling and the empting of the trench, along with the soil saturation process, modifications to the infiltration paths can be observed, making the process too complex to be simulated with mathematical models (Siriwardene et al. 2007a; Siriwardene et al. 2007b; Freni et al. 2009). Under particular circumstances, such as long trenches with one dimension much longer than the others, infiltration can be considered as a two-dimensional phenomenon. If the soil is homogeneous for a sufficient depth, the infiltration paths become linear and vertical at some distance below the bottom of the infiltration structure [Fig. 2(a)]. The model introduces the concept of an "effective area" as the horizontal area below the trench bottom where the infiltration paths become linear and parallel, so the phenomenon can be considered one-dimensional.

According to this definition, it is possible to use a onedimensional model to estimate the infiltration flow rate (Freni et al. 2009, 2004). This assumption has the drawback of neglecting the infiltration process around the BMP structure and assuming equilibrium between the stored water volume in the structure and the infiltrated volume in the soil where the flow paths are vertical [Fig. 2(b)]. The model simulates the hydraulics of an infiltration structure that is supposed to operate as a nonlinear reservoir, equipped with a weir that simulates the overflows to the drainage system or the catchment surface when the infiltration device reaches saturation [Fig. 2(b)]. Thus, the continuity equation can be written as follows:

$$
Q_{\text {in }}-Q_{w}-Q_{\text {inf }}=\frac{d V}{d t}
$$

where $V=$ volume stored in the structure; $Q_{\text {in }}=$ inflow from the contributing catchment; $Q_{\text {inf }}=$ infiltration flow; and $Q_{w}=$ outflow from the weir.

The outflow discharge $Q_{w}$ is evaluated here for a simple rectangular weir with a width equal to the width $B$ of the infiltration 
structure. The discharge can be computed with the following formula:

$$
Q_{w}=\mu_{W} B h \sqrt{2 g h}
$$

where $g=$ acceleration due to gravity; $h=$ water depth over the weir; and $\mu_{w}=$ weir coefficient, which is assumed to be equal to 0.4 according to the literature (Marchi and Rubatta 1981).

The infiltration flow $Q_{\text {inf }}$ is evaluated using the Green-Ampt equation (Green and Ampt 1911)

$$
Q_{\text {inf }}=\min \left\{Q_{\text {in }} ; k_{s}\left[1-\frac{\psi\left(\vartheta_{s}-\vartheta_{0}\right)}{F}\right] A_{\text {eff }}\right\}
$$

where $\theta_{s}$ and $\theta_{0}=$ saturated and initial moisture contents, respectively; $\psi=$ capillary suction; $F=$ cumulative infiltration volume; and the other symbols have the same definitions as given above. Also, $A_{\text {eff }}$ is the "effective infiltration area" (defined above), and it is the horizontal area below the bottom of the structure where the infiltration paths become linear and vertically parallel. According to the definition of the effective area, the infiltration phenomena can be analyzed using a one-dimensional approach.

The Green-Ampt equation allows us to consider the horizontal infiltration discharge, but on the other hand, it requires a better estimation of the effective infiltration area, which cannot be simply defined as a part of the physical infiltration structure's surface. Once $A_{\text {eff }}$ is defined, the simplified model approach simulates the clogging processes inside the infiltration structure by considering the mass balance for the suspended solids on a rainfall event scale

$$
\begin{aligned}
\Delta M_{\text {sed }} & =M_{\text {sed,in }}-M_{\text {sed,out }} \\
& =\int_{0}^{T_{\text {tot }}} Q_{\text {in }}(t) \cdot C_{\text {in }}(t) d t-\int_{0}^{T_{\text {tot }}} Q_{w}(t) \cdot C_{w}(t) d t
\end{aligned}
$$

where $\Delta M_{\text {sed }}=$ variation of the mass captured inside the structure; $M_{\text {sed,in }}$ and $M_{\text {sed,out }}$ represent, respectively, the mass inflow from the catchment and mass outflow by the weir to the sewer; $Q_{\text {in }}$ and $Q_{w}=$ inflow and outflow discharges, respectively; $C_{\text {in }}$ and $C_{w}$ = suspended solid concentrations; and $T_{\text {tot }}=$ duration of the rainfall event. The distribution of the solids on the bottom of the infiltration structure is assumed to be uniform; this assumption neglects the accumulation of solids on the wall and it is supported by the fact that such solids, which come from the catchment washoff, are usually not cohesive (Ashley et al. 2006).

The inflow $Q_{\text {in }}$ and suspended solid concentration $C_{\text {in }}$ are evaluated with the lumped conceptual model flow and sediment loads from the catchment, as described in the previous paragraph. Here, $A_{\text {eff }}$ is the most relevant model parameter, and two functional relationships need to be found to assess this parameter:
1. The correlation between the effective infiltration area for the clean structure condition $A_{\text {eff, }}$ and the geometrical trench bottom area $A$, which gives $A_{\text {eff, }, 0}$ for each infiltration structure; and

2. The correlation between the sediment level in the infiltration BMP and the effective infiltration area for the clogged condition $A_{\text {eff }}$ to evaluate the change to $A_{\text {eff }}$ during the structure's life cycle.

These correlations were investigated in a previous study (Freni et al. 2009) via the VSF-MODFLOW 2000 model (McDonald and Harbaugh 1983; Thoms et al. 2006; Winston 1997). This model, which was calibrated by an experimental campaign, accurately simulates real phenomena; it is able to analyze several infiltration structures by employing a physically based model and the adopted simplified model, thereby obtaining the desired correlation functions.

\section{Centralized Storage Tank Model}

Centralized storage tanks were simulated by the nonlinear reservoir approach. The adopted equations are equivalent to Eqs. (1) and (2) minus the infiltration term. The storage tank pollution interception capacity was computed by the mass balance equation [Eq. (4)]. The storage tank is simulated as a catch basin in terms of its outflowing pollutant concentrations and the intercepted mass at the end of the rainfall event, and the tank is assumed to be cleaned at the end of each rainfall event. Since the present paper is concerned with the quality of the receiving water, the simulated tanks that operate as catch basins are able to isolate the first part of the inflow hydrograph until they are completely filled.

More specifically, when the discharge exceeds a fixed threshold value that is compatible with the WWTP, a weir overflow device diverts the exceeding discharge into the tank. The water level in the tank rises until the maximum capacity is reached. When the tank is full, the overflow device diverts the excess discharge into the RWB, thus bypassing the tank. The overflow device activation threshold was set to five times the average dry weather flow (which is the normal design threshold level used in Italy). The overflow structure efficiency accounted for the fact that the discharge into the WWTP is not always fixed during rainfall events because of well-known hydraulic energy issues (Butler and Davies 2000). This aspect was accounted for by assuming an asymptotic exponential profile and a superior limiting discharge. Specifically, the following equation was employed for the CSO model (Mannina and Viviani 2009; Mannina 2005):

$$
\begin{cases}r_{d}=\frac{Q_{\mathrm{WWTP}}}{Q_{n}}=\frac{Q_{\text {sewer }}}{Q_{n}} & Q_{\text {sewer }} \leq Q_{\mathrm{th}} \\ r_{d}=\frac{Q_{\mathrm{WWTP}}}{Q_{n}}=r_{d 1}+\left(r_{d 2}-r_{d 1}\right) \cdot\left(1-e^{\left[\left(r_{d 1}-Q_{\text {sewer }}\left(Q_{n}\right) /\left(r_{d 2}-r_{d 1}\right)\right]\right.}\right) & Q_{\text {sewer }}>Q_{\mathrm{th}}\end{cases}
$$

where $Q_{\mathrm{WWTP}}=$ flow passing through the CSO that generally represents the WWTP inflow; $Q_{n}=$ dry weather flow; $Q_{\text {sewer }}=$ CSO inflow-rate; $r_{d 1}$ and $r_{d 2}=$ dilution coefficients; and $Q_{\mathrm{th}}=$ minimum constant values of the flow passing through the CSO without being intercepted (Fig. 3). As $Q_{\text {sewer }}$ grows higher than $Q_{\text {th }}$, part of sewer discharge is intercepted by the weir and the water level in 


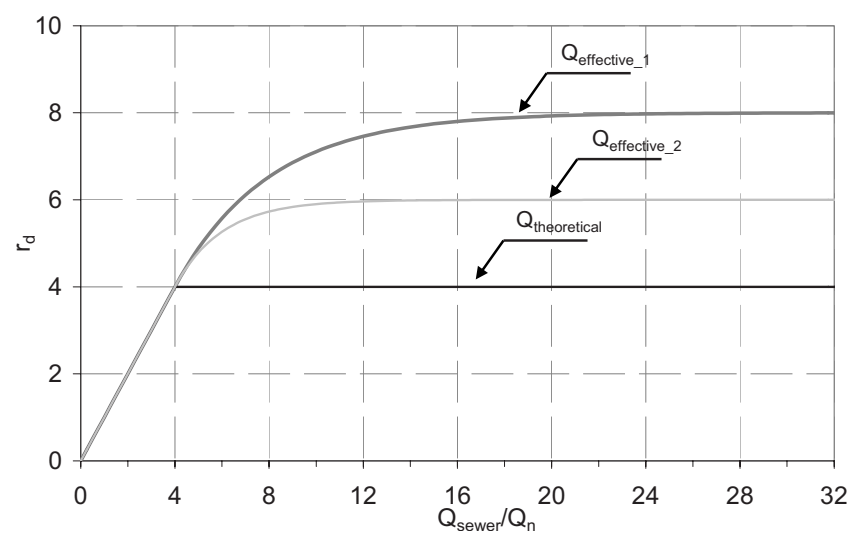

Fig. 3. CSO behavior during rainfall events

the CSO increases as well, thereby increasing the hydraulic gradient along the pipe continuing to the WWTP. Such physical process increases the discharge flowing to the WWTP that can be well represented by the asymptotic exponential law presented in Eq. (5).

The asymptotic values of the effective flow to the WWTP $\left(Q_{\text {eff }}\right)$ and $Q_{\text {th }}$ were evaluated by the following equations:

$$
\begin{aligned}
& Q_{\text {th }}=r_{d 1} \cdot Q_{n} \\
& Q_{\text {eff }}=r_{d 2} \cdot Q_{n}
\end{aligned}
$$

According to Italian standards, the ranges of $r_{d 1}$ and $r_{d 2}$ are 3-4 and 6-10, respectively; we set the values of $r_{d 1}$ and $r_{d 2}$ to 5 and 8, respectively, in the present study.

\section{Case Study}

The Parco d'Orlèans urban catchment is located on the campus of the University of Palermo, Italy. Its total drainage area is 12.8 ha with $68 \%$ imperviousness; the drainage network is combined, and it is composed of circular and egg-shaped concrete conduits.

Rainfall data have been collected since 1993 with a tipping bucket rain gauge and a data logger with a maximum resolution of $1 \mathrm{~min}$ (Aronica and Cannarozzo 2000). The discharge data have been collected with a temporal resolution of $1 \mathrm{~min}$ since 1993 with an ultrasonic flow meter installed at the basin's outlet (Fig. 4). From this data archive, a continuous rainfall series lasting six years was extracted and used for the simulations. Table 1 shows the main rainfall characteristics along with the average antecedent dry weather period (ADWP).

Ackers et al. (1996) found that sewer sediments are characterized by a $d_{50}$ of $10-1,000 \mu \mathrm{m}$ and a density of $1-2.7 \mathrm{~kg} / \mathrm{m}^{3}$. More specifically, Ackers et al. (1996) classified the sewer sediments as sanitary solids $\left(d_{50}=40 \mu \mathrm{m}\right.$ and a specific average density of 1.4$)$, storm-water solids $\left(d_{50}=60 \mu \mathrm{m}\right.$ and a specific average density of 2$)$, and grits $\left(d_{50}=750 \mu \mathrm{m}\right.$ and a specific average density of 2.6). Furthermore, solids less than $0.15 \mathrm{~mm}$ in size were determined to be in suspension, and inorganic particles greater than $0.15 \mathrm{~mm}$ were considered as part of the bed load. According to Chebbo et al. (1990), it is possible to differentiate between dry and wet weather periods based on the sizes of the finest particles. More specifically, a dry weather period is characterized by a particle density between 1,100 and $1,800 \mathrm{~kg} / \mathrm{m}^{3}$, while the density ranges from $2,400-2,600 \mathrm{~kg} / \mathrm{m}^{3}$ for a wet weather period.

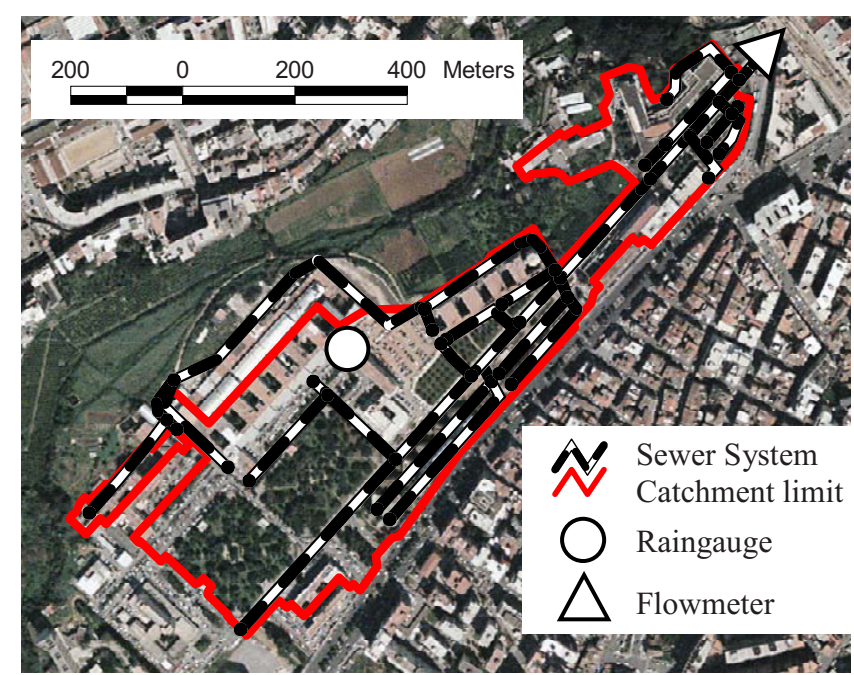

Fig. 4. Experimental catchment of Parco d'Orlèans (Palermo, Italy)

Two classes of particles were considered in the adopted model: fine particles (mean diameter $d_{50}=50 \mu \mathrm{m}$; specific gravity $s$ $=1.6)$ and coarse particles $\left(d_{50}=500 \mu \mathrm{m} ; s=2.0\right)$. Fine particles are mainly transported as suspended load, while coarse particles are transported as bed load or suspended load, depending on the characteristics of the flow. Actually, coarse particles considered here have a specific gravity that is slightly lighter than the value given in the literature; this result, which is from a sewer sediment survey by La Loggia and Viviani (1990), is probably due to the organic components.

A specific survey was carried out to characterize the soils' infiltration capacities. The experimental catchment is characterized by sandy soils with an uneven distribution of loam. Loams are present in small patches, usually over areas smaller than $1,000 \mathrm{~m}^{2}$. Thus, they can locally affect soil infiltration capacities, and their position cannot be easily forecasted because of the fact that they are not aggregated in a continuous layer. The soil characteristics were estimated by both field infiltration experiments and laboratory measurements (Liguori 2002). Two main soil types were considered in the present study: sand and loamy sand (or sand with loam inclusions). The MODFLOW model was calibrated using the results of the soil hydraulic conductivity laboratory analysis and field experimentation (Liguori 2002). More specifically, the laboratory studies provided initial values of the soil permeability and the specific porosity, whereas models of the field infiltration experiments refined the calibration by comparing the modeling infiltration discharges with the time-dependent variations to the infiltrated volume. Fine calibration was thus performed by minimizing the round-square-mean error between the modeled discharges and the monitored data. The Green-Ampt parameters were obtained from the field infiltration experiments and are reported in Table 2.

The drainage system is depicted in Fig. 3, and it consists of circular and egg-shaped concrete pipes with diameters ranging between 300 and $600 \mathrm{~mm}$. The drainage system is combined, and a CSO device is present at the catchment closure's cross section. The water quantity and quality data in the sewer have been collected before the CSO device for the whole monitoring period (6 years). Water quality data (TSS, BOD, and COD) were collected between December 1999 and January 2000 using a 24-bottle automatic sampler. The temporal resolution of the dry weather data are equal to $1 \mathrm{~h}$, and the temporal resolution of the wet weather is 
Table 1. Adopted Rainfall Series Characteristics

\begin{tabular}{|c|c|c|c|c|c|c|}
\hline & $1994^{\mathrm{a}}$ & 1995 & 1996 & 1997 & 1998 & 1999 \\
\hline Rainfall depth (mm) & 285 & 552 & 655 & 602 & 634 & 582 \\
\hline $\mathrm{N}^{\circ}$ events (rainfall depth $>2 \mathrm{~mm}$ ) & 22 & 56 & 63 & 73 & 66 & 57 \\
\hline Average ADWP (days) & 5.5 & 4.5 & 3.8 & 4.3 & 4.1 & 4.6 \\
\hline Average rainfall intensity $(\mathrm{mm} / \mathrm{h})$ & 7.2 & 8.5 & 9.7 & 7.7 & 5.8 & 6.2 \\
\hline Maximum 5-min rainfall intensity $(\mathrm{mm} / \mathrm{h})$ & 37.8 & 42.2 & 57.8 & 36.5 & 40.2 & 42.8 \\
\hline Maximum 10-min rainfall intensity $(\mathrm{mm} / \mathrm{h})$ & 27.3 & 28.5 & 34.3 & 22.4 & 33.6 & 29.2 \\
\hline Maximum 15 -min rainfall intensity $(\mathrm{mm} / \mathrm{h})$ & 22.1 & 23.2 & 25.6 & 19.8 & 22.7 & 24.2 \\
\hline
\end{tabular}

${ }^{\mathrm{a}} 6$ months.

equal to $15 \mathrm{~min}$. The wet weather sampling was activated by connecting the sampler to a nearby rain gauge, and the data were used for calibrating the rainfall-runoff model and the sewer propagation model (Mannina 2005; Freni et al. 2009). The calibration results are omitted here as they have been reported in the cited literature, but the calibrated parameters are reported in Table 3.

\section{Results and Discussion}

The aim of our analysis is to compare the different water quality mitigation plans that aim to reduce the polluting load discharged into the RWB. Several possible mitigation configurations were considered and are described in Fig. 1; these configurations include both local infiltration and source storage and centralized end-of-pipe storage tanks. Since this is a planning study, the structures' dimensions were synthesized by means of the specific treatment volume $C$, which is defined as the treatment volume available at each mitigation structure divided by the extension of the directly connected impervious surface.

For the present study, various volumes of $C$, ranging between 10 and $40 \mathrm{~m}^{3} /$ ha, were used for all of the considered mitigation measures. Also, both sandy and loamy sand soils were considered. In the mixed configuration, it was initially assumed that $50 \%$ of the total mitigation volume was provided by infiltration source controls and $50 \%$ was provided by centralized storage tanks. Then, different mixed configurations were analyzed by changing the relative percentages of the infiltration and storage.

This study was performed by running a continuous simulation for the entire 6-year period. The results from the different scenarios were determined for the whole analysis period, but only the results regarding overflow volumes and TSS loads are presented here for sake of brevity.

Figs. 5 and 6 show the results of the 6-year analysis for the different design criteria and types of soil. These figures show the cumulated water volume and TSS mass that is discharged into the RWB by the CSO device. The volumes and masses were computed at the end of each rainfall event. From the resulted graphs (Fig. 7), some conclusions can be drawn:

Table 2. Selected Soils Characteristics

\begin{tabular}{lccc}
\hline & \multicolumn{2}{c}{ Soil } \\
\cline { 2 - 4 } Parameter & Unit & Loamy sand & Sand \\
\hline$\vartheta_{s}$ & & 0.43 & 0.44 \\
$\vartheta_{0}$ & 0.04 & 0.02 \\
$\psi$ & $\mathrm{m}$ & 0.1013 & 0.0935 \\
$K_{s}$ & $\mathrm{~cm} / \mathrm{h}$ & 6.12 & 23.4 \\
\hline
\end{tabular}

- End-of-pipe storm-water tanks provide better mitigation efficiencies compared with infiltration measures in soils with an average infiltration capacity (loamy sands); this suggests that centralized measures are more effective in reducing CSO volume and polluting loads;

- Source controls based on storage have lower efficiencies than infiltration because infiltrated storm water provides greater reduction to the runoff volumes delivered to the drainage system;

- A comparison between the source and centralized storage systems shows that the latter method provides higher efficiencies given the same specific design volume; this result is justified by the fact that centralized storage directly acts on CSO spills;

- When the soil infiltration capacity increases, infiltration BMPs give better performances in terms of both the overflow volume reduction and the TSS load mitigation; obviously, when the infiltration capacity is able to dispose of large storm-water volumes, the advantages derived by the use of centralized mitigation structures is compensated by the source control infiltration capacity; and

- Clogging has a non-negligible effect on the long-term efficiency; in sandy soils and a specific design volume of $40 \mathrm{~m}^{3} / \mathrm{h}$, for example, the infiltration structure volume is reduced by only $12 \%$ after 6 years, but for $10 \mathrm{~m}^{3} /$ ha, the effective volume was reduced by $40 \%$.

This last conclusion may be useful for infiltration structure maintenance schedule when the infiltration structure volume is reduced by the presence of sediments. Indeed, such a schedule may vary based on characteristics of loading from drainage area.

These results suggest that centralized mitigation measures provide the most robust and reliable solutions, but especially in dense urban areas, they are not easily applicable because of a lack of space. To solve this issue, mixed configurations were considered that use both source controls and centralized mitigation measures (with a 50/50 distribution). The results (Figs. 6 and 7) indicate that a mixture of source controls and end-of-pipe controls can be an efficient compromise between the mitigation efficiency and the space required for the structures.

Some interesting conclusions can be drawn from Fig. 7:

- For a loamy sand soil, a mixed configuration provides efficiency values between those of source control schemes and a centralized solution;

- In the case of CSO reduction efficiency, spill reduction and TSS reduction efficiency, the centralized and mixed configurations are close but the centralized appears slightly more efficient; and

- In case of more pervious soils, the mixed configuration gives efficiencies similar to that of the centralized solution for low design specific volumes, but for higher design specific vol- 
Table 3. Model Parameters and Calibrated Values

\begin{tabular}{|c|c|c|c|c|}
\hline & Parameter & Symbol & Unit & Value \\
\hline \multicolumn{5}{|c|}{ (a) Quantity module } \\
\hline \multirow[t]{5}{*}{ Input parameters } & Time simulation step & $\Delta t$ & S & 60 \\
\hline & Catchment surface & $A$ & $\mathrm{~m}^{2}$ & 128,000 \\
\hline & Simulation duration time & $T_{\text {event }}$ & Min & Variable \\
\hline & Percentage of impervious area & IMP & - & 0.68 \\
\hline & Dry weather flow & $Q_{d}$ & $\mathrm{~m}^{3} / \mathrm{s}$ & 0.008 \\
\hline \multirow[t]{5}{*}{ Calibration parameters } & First reservoir constant & $K_{1}$ & Min & 8.41 \\
\hline & Second reservoir constant & $K_{2}$ & Min & 2.05 \\
\hline & Storage volume coefficient & $W_{0}$ & - & 0.35 \\
\hline & Gaukler-Strickler coefficient & $K_{s}$ & $\mathrm{~m}^{1 / 3} / \mathrm{s}$ & 70 \\
\hline & Continuous loss coefficient & $\Phi$ & - & 0.47 \\
\hline \multicolumn{5}{|c|}{ (b) Quality module } \\
\hline \multirow[t]{15}{*}{ Input parameters } & Residual mass after last event & $M_{r}$ & $\mathrm{~kg}$ & 0 \\
\hline & Street cleaning frequency & $d_{\mathrm{st}}$ & $\mathrm{D}$ & 0 \\
\hline & Street cleaning efficiency & $F_{\text {st }}$ & $\%$ & No service \\
\hline & Antecedent dry weather period & ADWP & $\mathrm{H}$ & Variable \\
\hline & TSS dry weather concentration & $\mathrm{TSS}_{\mathrm{dry}}$ & $\mathrm{mg} / \mathrm{L}$ & 200 \\
\hline & COD dry weather concentration & $\mathrm{COD}_{\text {dry }}$ & $\mathrm{mg} / \mathrm{L}$ & 700 \\
\hline & $\mathrm{BOD}_{5}$ dry weather concentration & $\mathrm{BOD}_{\text {dry }}$ & $\mathrm{mg} / \mathrm{L}$ & 400 \\
\hline & Correlation parameter COD-TSS & $f_{\mathrm{COD}}$ & - & 0.84 \\
\hline & Correlation parameter $\mathrm{BOD}_{5}$-TSS & $f_{\mathrm{BOD}}$ & - & 0.25 \\
\hline & Equivalent conduit & $\mathrm{Eq}$ & - & Egg shaped \\
\hline & Conduit diameter & $D$ & M & 1.44 \\
\hline & Conduit slope & $I$ & - & 0.015 \\
\hline & Equivalent sewer network length & $L_{e q}$ & M & 85 \\
\hline & Surface critical bed shear stress & $\tau_{\mathrm{cs}}$ & $\mathrm{N} / \mathrm{m}^{2}$ & 1.08 \\
\hline & Depth of the total sediment bed & $d_{\mathrm{tot}}$ & M & Variable \\
\hline \multirow[t]{12}{*}{ Calibration parameters } & Sewer sediment storage capacity & $\mathrm{CS}$ & $\mathrm{kg}$ & 1580 \\
\hline & Sewer sediment accumulation constant & $K_{\text {dep }}$ & $\mathrm{h}^{-1}$ & 0.0099 \\
\hline & Erosional resistance exponent & $B$ & - & 0.14 \\
\hline & Depth of weak layer & $d^{\prime}$ & M & $d_{\mathrm{tot}} / 3$ \\
\hline & Uniform critical bed shear stress & $\tau_{\mathrm{cu}}$ & $\mathrm{N} / \mathrm{m}^{2}$ & 4 \\
\hline & Buildup coefficient & Accu & $\mathrm{kg} / \mathrm{ha} \cdot \mathrm{d}$ & 8 \\
\hline & Decay coefficient & Disp & $d^{-1}$ & 0.07 \\
\hline & Washoff coefficient & Arra & $\mathrm{mm}^{-1}$ & 0.18 \\
\hline & Washoff factor & Wh & - & 0.64 \\
\hline & Erosion coefficient & $M$ & $\mathrm{~g} / \mathrm{s}$ & 107.68 \\
\hline & Suspension delay & $K_{\text {susp }}$ & $\mathrm{h}$ & 0.07 \\
\hline & Bed transport delay & $K_{\text {bed }}$ & $\mathrm{h}$ & 0.05 \\
\hline
\end{tabular}

umes, the mixed configuration performs better than the centralized one.

This last conclusion can be explained by considering the resuspension process that takes part inside sewer pipes. In the presence of source controls and depending on their design volume, several rainfall events do not produce sewer discharges reducing the resuspension of solids that settle during dry periods. In Scheme 2 (source control only), this positive effect is balanced by the absence of end-of-pipe measures so that every spill from the CSO device results in a polluting discharge to the RWB.

To confirm such considerations, specific analyses have been performed by varying the balance between local infiltration and centralized storage employing two different soil types (loamysand and sand). More specifically, a global specific volume $C$ of $40 \mathrm{~m}^{3} /$ ha has been split between local infiltration and centralized storage. Fig. 8 shows the efficiencies depending on the percentage of local infiltration employed for the mixed configuration. In loamy-sand soils [Fig. 8(a)], the contribution of infiltration measures to storm-water runoff reduction is low, and the use of centralized storage would be suggested as the only mitigation practice. In sandy soils [Fig. 8(b)], infiltration measures reduce runoff and sewer resuspension, and the presence of small storage tanks limits the impacts of CSO spills, greatly improving the overall efficiency.

Finally, it is notable that for combined sewers it is necessary to simulate not only the performance of the SS and the tanks but also the processes at the WWTP to completely understand the effect of the tanks in reducing the impact of storm water on the RWB. In fact, emptying the tank at the end of a rainfall event can adversely affect the efficiency of the plant, especially regarding to biologic removal of BOD, nutrients, and sedimentation because 

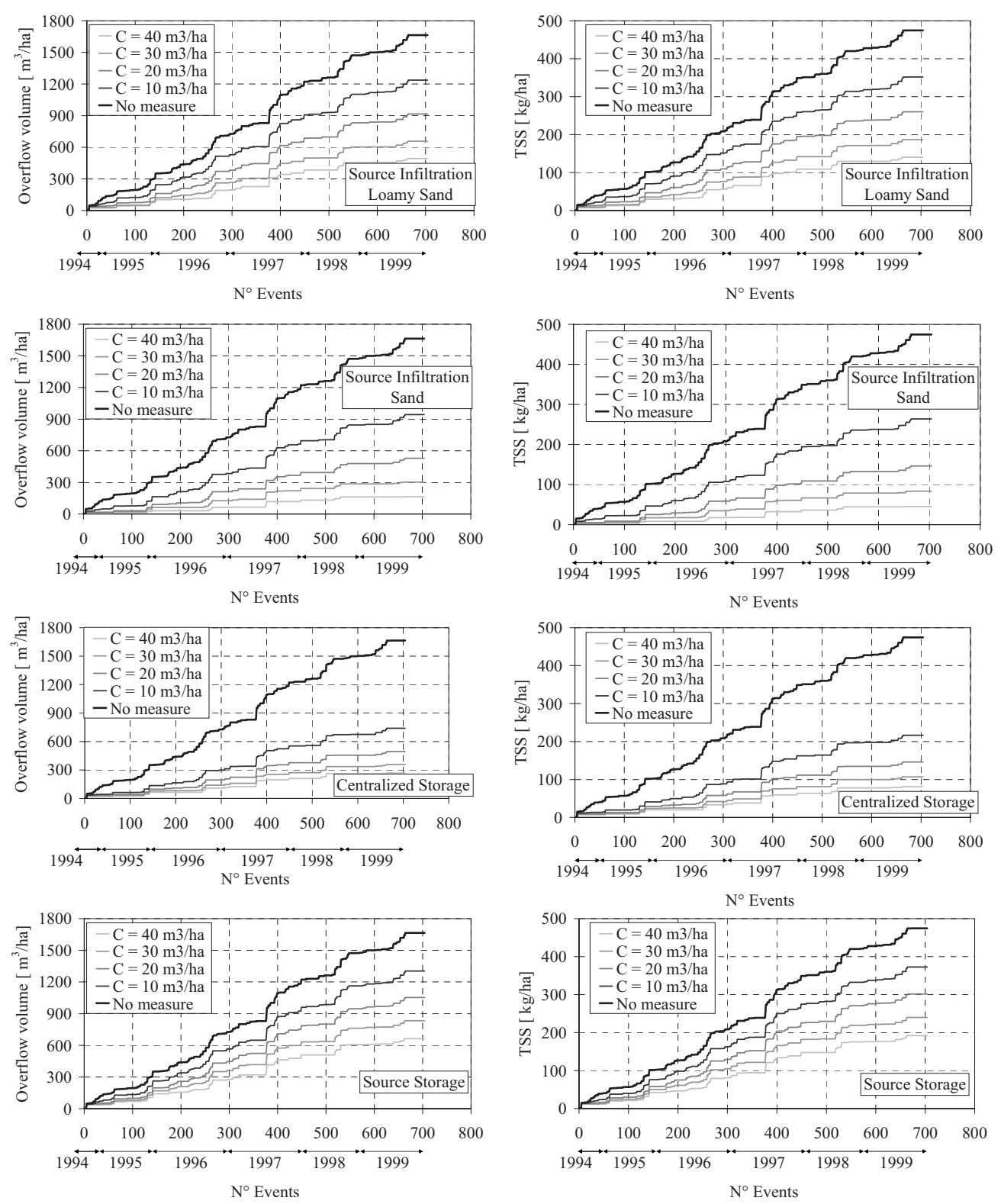

Fig. 5. Cumulative overflow volumes and TSS loads discharged to the RWB in different mitigation schemes involving source controls or centralized mitigation measures

of the increase of organic and hydraulic loads (Durchschlag 1990; Lau et al. 2002; Calabrò and Viviani 2006).

\section{Conclusions}

A comparison among different mitigation measures based on modeling investigations has been presented. Particularly, a parsimonious model, which was developed in previous studies, was employed to evaluate the mitigation efficiency of different BMP schemes, including infiltration and storage facilities and both possible source controls and centralized structures. Using a case study of an urban catchment in Palermo, some general conclusions can be drawn:

- Centralized techniques are more robust and can be effective also with small specific design volumes; the tradeoff between the higher land requirements of centralized mitigation structures and their efficiency is thus confirmed by the present study, and centralized measures should be used in cases where local infiltration is not feasible or the soil permeability is low.

- BMPs based on storm-water infiltration process can be effective if the soil infiltration capacity allows their use, but their efficiency can be reduced by clogging (in the presented case study, small infiltration structures were $40 \%$ clogged after only 6 years of service); clogging phenomena are greatly dependent on total treated volumes and should be taken into account when defining design volumes in relation to the expected mitigation structure life expectancy, especially considering the difficulties of maintenance of such structures.

- Mixed configurations, involving both source controls and centralized techniques, are, in some cases, more efficient than centralized controls (maintaining the same design specific volume) by avoiding frequent sewer flushing during wet periods and protecting receiving waters from frequent CSO spills; in such configurations, the system failure risk due to the clogging phenomena is mitigated by the presence of a local infiltration 

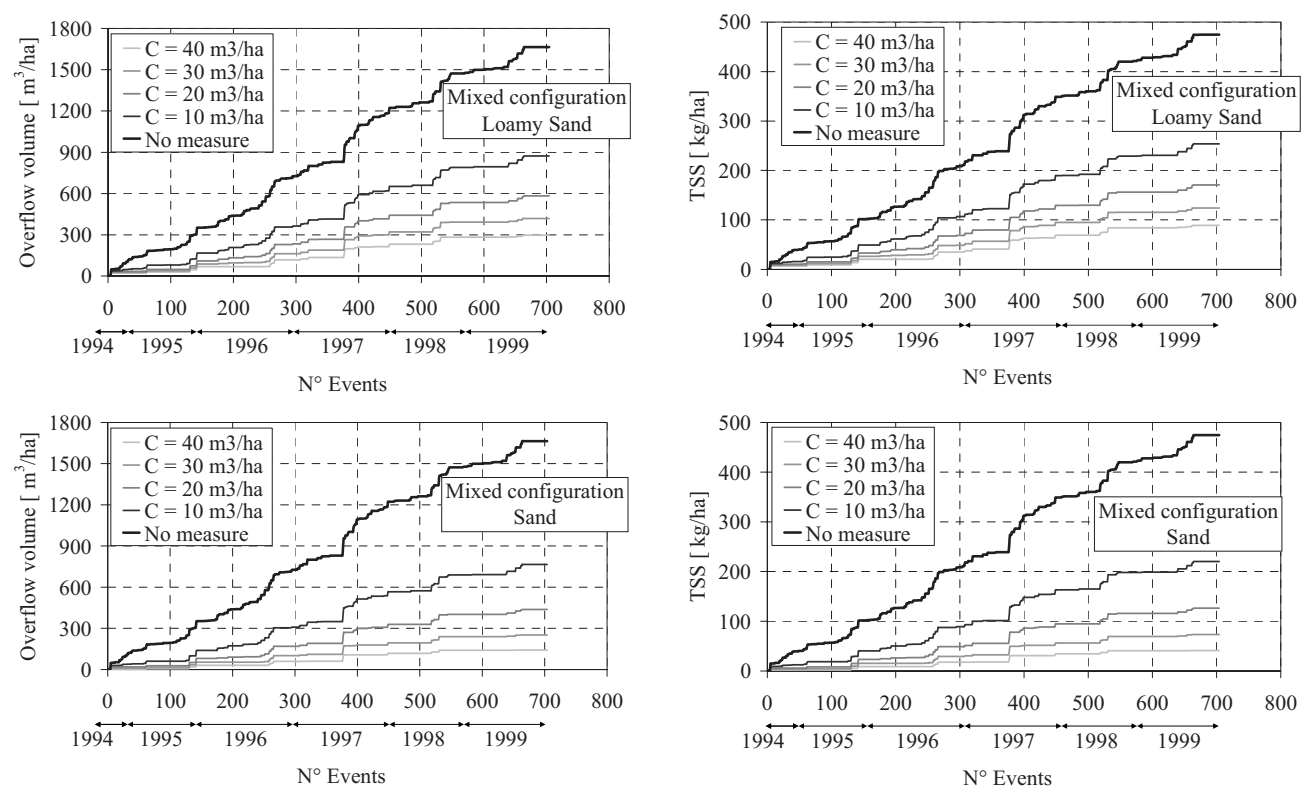

Fig. 6. Overflow volume and TSS load reduction in mixed configurations
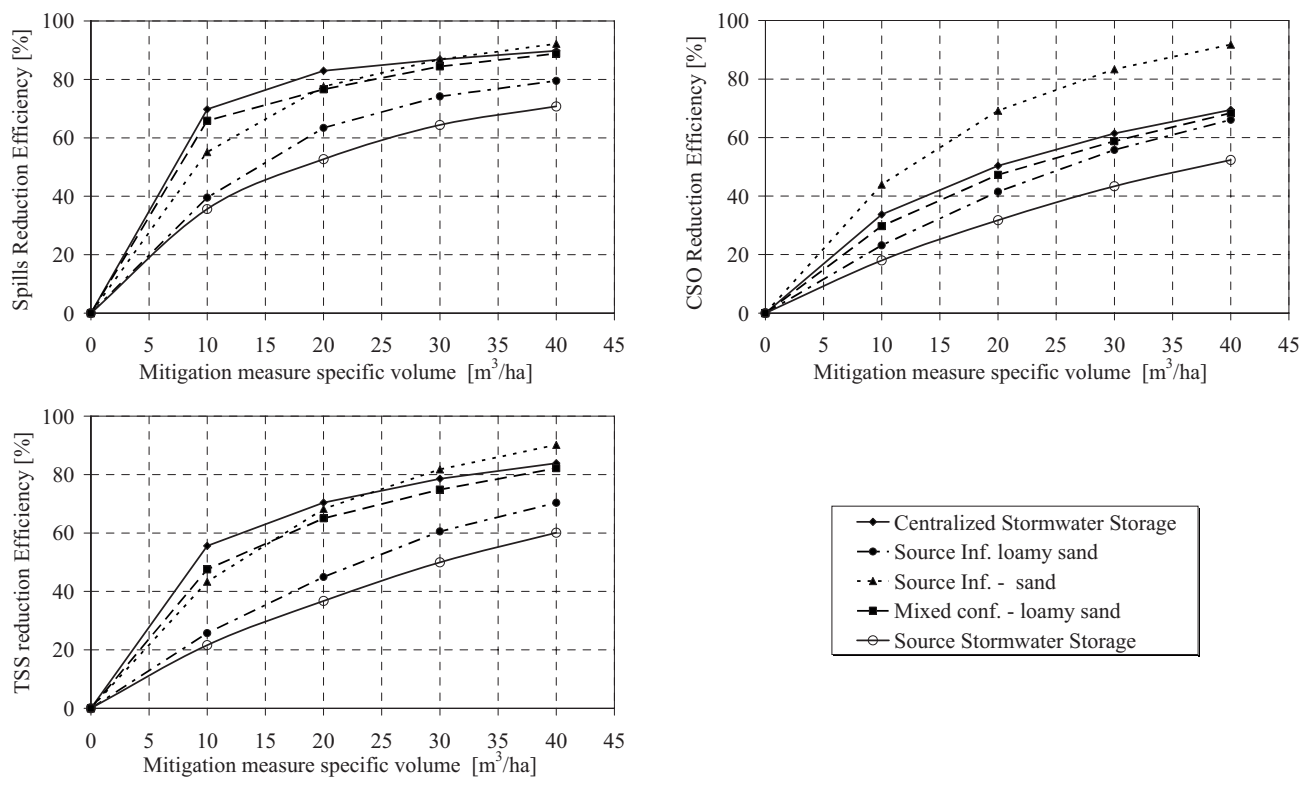

Fig. 7. Overall storm-water management efficiency in different configuration schemes

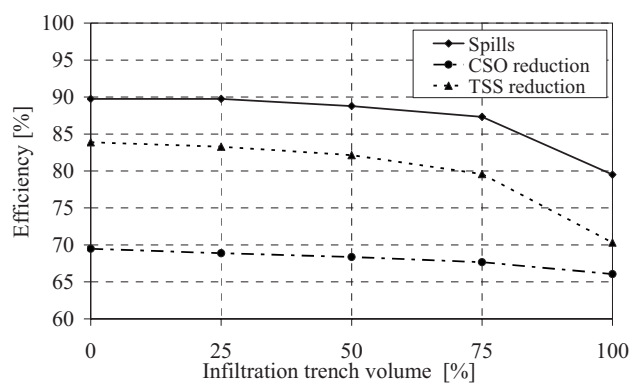

(a)

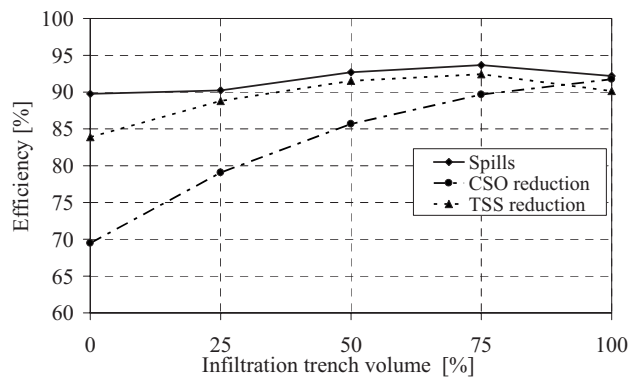

(b)

Fig. 8. Comparison of different mixed configurations in (a) loamy sand; (b) sandy soils 
structure and centralized storage that may partially contribute to the inefficiency of clogged infiltration structures.

Such applications may be also used for a priori evaluations of maintenance needs and frequencies, especially for infiltration structures where the mitigation efficiency is greatly influenced by clogging. An important issue to consider in future research is the effect of the introduction of the tanks on the WWTP to determine the tank volumes that minimize the total pollution load in the RWB.

\section{References}

Ackers, J. C., Butler, D., and May, R. W. P. (1996). "Design of sewers to control sediment problems." Rep. No. 141, Construction Industry Research and Information Association, London.

Alfakih, E., Barraud, S., Azzout, Y., and Chocat, B. (1995). "Urban stormwater-The analysis of the failure of the alternative techniques and the management of quality." Water Sci. Technol., 32(1), 33-39.

Alley, W. M., and Smith, P. E. (1981). "Estimation of accumulation parameters for urban runoff quality modelling." Water Resour. Res., 17(6), 1657-1664.

Aronica, G., and Cannarozzo, M. (2000). "Studying the hydrological response of urban catchments using a semi-distributed linear non-linear model." J. Hydrol., 238(1-2), 35-43.

Artina, S., Bolognesi, A., Liserra, T., and Maglionico, M. (2007). "Simulation of a storm sewer network in industrial area: Comparison between models calibrated through experimental data." $J$. Environmental Modeling and Software, 22(8), 1221-1228.

ASCE. (1998). "Urban runoff quality management." ASCE Manual and Report on Engineering Practice N.87, ASCE, Reston, Va.

Ashley, R. M., Bertrand-Krajewski, J. L., Hvitved-Jacobsen, T., and Verbanck, M. (2006). "Solids in sewers: Characteristics, effects and control of sewer solids and associated pollutants." Water Intelligence Online Report, IWA Publishing, London.

Bertrand-Krajewski, J.-L., Bardin, J.-P., and Gibello, C. (2006). "Long term monitoring of sewer sediment accumulation and flushing experiments in a man-entry sewer." Water Sci. Technol., 54(6-7), 109-117.

Bledsoe, B. (2002). "Stream erosion potential and stormwater management strategies." J. Water Resour. Plann. Manage., 128(6), 451.

Browne, D., Deletic, A., Mudd, G. M., and Fletcher, T. D. (2008). "A new saturated/unsaturated model for stormwater infiltration systems." Hydrolog. Process., 22(25), 4838-4849.

Butler, D., and Davies, J. (2000). Urban drainage, E \& FN Spon, New York.

Calabrò, P. S., and Viviani, G. (2006). "Simulation of the operation of detention tanks." Water Res., 40(1), 83-90.

Chebbo, G., Musquere, P., Milisic, V., and Bachoc, A. (1990). "Solides transférés dans les réseaux d'assainissement." Caractéristique hydrodynamiques et charges polluantes, Rapport IMF, Toulouse, France, 7.

Despotovic, J., Desbordes, M., and Vukmirovic, V. (1995). "Rainfall data analysis for alternative solutions of urban storm drainage systems." Proc., 2nd Int. Conf. on Innovative Technologies in Urban Storm Drainage, Vol. 1, GRAIE, Lyon, France, 47-58.

Durchschlag, A. (1990). "Long-term simulation of pollutant loads in treatment plant effluents and combined sewer overflows." Water Sci. Technol., 22(10-11), 69-76.

Emerson, C. H., Welty, C., and Traver, R. G. (2005). "Watershed-scale evaluation of a system of storm water detention basino." J. Hydrol. Eng., 10(3), 237-242.

Freni, G., Maglionico, M., Mannina, G., and Viviani, G. (2008). "Comparison between a detailed and a simplified integrated model for the assessment of urban drainage environmental impact on an ephemeral river." J. Urban Water, 5(2), 87-96.

Freni, G., Mannina, G., and Viviani, G. (2009). "Stormwater infiltration trenches: a conceptual modeling approach." Water Sci. Technol., 60(1), 185-199.
Freni, G., Oliveri, E., and Viviani, G. (2004). "Infiltration facilities design: comparison between simplified approaches and detailed physically based modeling." Proc., 5th Int. Conf. on Sustainable Techniques and Strategies in Urban Water ManagementNOVATECH, GRAIE, Lyon, France, 1245-1252.

Freni, G., and Schilling, W. (2001). "Total pollution analysis and control: Urban stormwater management." Integrated Urban Water Systems (IUWS)_COST 624 Optimal Management of Wastewater Systems, 〈http://www.ensic.inpl-nancy.fr/COSTWWTP/〉 (2009).

Green, W. H., and Ampt, G. A. (1911). "Studies on soil physics. I. The flow of air and water through soil.” J. Agric. Sci., 9(1), 1-24.

Harremoës, P., and Madsen, H. (1999). "Fiction and reality in the modeling world-balance between simplicity and complexity, calibration and identifiability, verification and falsification." Water Sci. Technol., 39(9), 1-8.

Hatt, B. E., Deletic, A., and Fletcher, T. D. (2006). "Integrated treatment and recycling of stormwater: A review of Australian practice." J. Environ. Manage., 79(1), 102-113.

Hatt, B. E., Fletcher, T. D., and Deletic, A. (2007). "Treatment performance of gravel filter media: Implications for design and application of stormwater infiltration systems." Water Res., 41(12), 2513-2524.

Hatt, B. E., Fletcher, T. D., Walsh, C. J., and Taylor, S. L. (2004). "The influence of urban density and drainage infrastructure on the concentrations and loads of pollutants in small streams." Environ. Manage. (N.Y.), 34(1), 112-124.

Huber, W. C. (1996). "BMP simulation using the U.S. EPA storm water management model (SWMM)." Proc., 7th Int. Conf. on Urban Storm Drainage, IAHR/IAWQ, Hannover, Germany, 1629-1634.

Jewell, T. K., and Adrian, D. D. (1978). "SWMM storm water pollutant washoff function." J. Environ. Eng. Div., 104(5), 1036-1040.

La Loggia, G., and Viviani, G. (1990). "Controllo, verifica e calibrazione di modelli di piena in un bacino urbano in Sicilia." Proc., XXII Convegno di Idraulica e Costruzioni Idrauliche, Università di Cosenza, Cosenza, Italy, 1234-1241 (in Italian).

Lau, K. T., Butler, D., and Schutze, M. (2002). "Is combined sewer overflow spill frequency/volume a good indicator of receiving water quality impact?" Urban Water, 4(2), 181-189.

Liguori, V. (2002). Le formazioni geologiche affioranti nella Fossa della Garofala, Regional Government of Sicily, Palermo, Italy (in Italian).

Mannina, G. (2005). "Integrated urban drainage modeling with uncertainty for stormwater pollution management.” Ph.D. thesis, Università di Catania, Italy.

Mannina G., Freni G., and Viviani G. (2004). "Modeling urban stormwater impact mitigation by using bmps and storage tanks." Proc., European Geophysical Union-I General Assembly, Vol. 6, COSIS, Nizza, France.

Mannina, G., and Viviani, G. (2009a). "Separate and combined sewer systems: a long-term modeling approach.” Water Sci. Technol., 60(3), 555-565.

Mannina, G., and Viviani, G. (2009b). "An urban drainage stormwater quality model: Model development and uncertainty quantification." $J$. Hydrol.

Marchi, E., and Rubatta, A. (1981). Meccanica dei fluidi: Principi e applicazioni (Fluid mechanics: Principles and applications), UTET, Milan, Italy.

Mays, L. W. (2001). Stormwater collection systems design handbook, McGraw-Hill, New York.

McDonald, M. G., and Harbaugh, A. W. (1983). "A modular threedimensional finite-difference groundwater flow model." Techniques of water resources investigations, modeling techniques, EPA, Reston, Va.

Niemczynowicz, J. (1994). "New aspects of urban drainage and pollution reduction towards sustainability." Water Sci. Technol., 30(5), 269277.

Sansalone, J. J., and Buchberger, S. G. (1995). "An infiltration device as a best management practice for pollutants in urban highway runoff." Water Sci. Technol., 32(4), 119-125.

Sieker, H., and Klein, M. (1998). "Best management practices for 
stormwater-runoff with alternative methods in a large urban catchment in Berlin, Germany." Water Sci. Technol., 38(10), 91-97.

Siriwardene, N. R., Deletic, A., and Fletcher, T. D. (2007a). "Clogging of stormwater gravel infiltration systems and filters: Insights from a laboratory study." Water Res., 41(7), 1433-1440.

Siriwardene, N. R., Deletic, A., and Fletcher, T. D. (2007b). "Preliminary studies of the development of a clogging prediction method for stormwater infiltration systems." Water Practice and Technology, 2(2), 162-169.

Thoms, R. B., Johnson, R. L., and Healy, R. W. (2006). "User's guide to the Variably Saturated Flow (VSF) Process for MODFLOW." U.S. Geological Survey techniques and methods 6-A18, U.S. Geological Survey, Reston, Va.
Tomicic, B., Clifforde, I. T., Mark, O., Yde, L., and Dudley, J. (1999). "Integrated catchment simulator (ICS) - Development and applications." Proc., 3rd DHI Software Conf., 〈www.dhi.dk/softcon/ index.htm>.

Vaes, G., and Berlamont, J. (1999). "Emission predictions with a multilinear reservoir model." Water Sci. Technol., 39(2), 9-16.

Vaes, G., and Berlamont, J. (2004). "Source control design using continuous long term modeling." Proc., 6th Int. Conf. on Urban Drainage Modeling (UDM'04), P. Krebs and L. Fucks, eds., Institute for Urban Water Management, Dresden, 599-608.

Winston, R. B. (1997). "MODFLOW help file." HTML Documentation, 〈http://water.usgs.gov/nrp/gwsoftware/mfgui4/modflow-gui.html〉 (2009). 